\title{
Gender Differences in Athletic and Academic Cultures on a University Campus
}

\author{
Kenneth Sellers \\ Northwestern Missouri State University \\ Kelsey Kowalski \\ Jabil \\ George B. Yancey \\ Southeast Missouri State University
}

\begin{abstract}
In order to explore the differences between a student's academic life and a scholarathlete's sports life, we investigated the organizational cultures of a university's academic departments and sports teams by surveying 259 students and 230 student-athletes. We found the academic cultures to be more clannish (family oriented) and the sports cultures more market (performance and results) driven. For the female athletes, we found a negative relationship between clan culture and satisfaction with their sports team, while for everyone else (male and female students and male athletes) clan culture was positively related to satisfaction with academic department or sports team. Relatedly, for the female athletes, the relationship between market culture and satisfaction with their sports team was positive, while for everyone else (male and female students and male athletes) market culture was negatively related to satisfaction with academic department or sports team. This suggests that there are important differences between the experiences of male and female student-athletes. We also found the participants in the business school to be less clannish than those in the other schools and colleges. We discuss the practical implications of these results for coaches of male and female athletes and for campus leaders of academic departments.
\end{abstract}

Keywords: organizational culture, student life, student-athletes, gender differences, coaching

\section{Gender Differences in Athletic and Academic Cultures on a University Campus}

How does the student-athlete experience differ from that of the typical university student? To explore this question, we examined the cultures of university athletic teams and of university academic departments. 
The following quote captures college life for many students across America:

College in the United States is an odd mixture of higher learning and youth culture for its students, and it has been for over a hundred years. In the late nineteenth century American undergraduates themselves invented the youth culture of outside-the-classroom-college, naming it "college life" and passing it down to future student generations. (Moffatt, 1991, p. 44)

While students acknowledge that they are in college to learn, in his anthropological study of college life at Rutgers, Moffatt (1991) found that for the ordinary mid-week of mid-semester, students went to class about four hours a day and studied about two hours a day. That left an abundance of out-of-classroom time. Some students were involved in organized extracurricular activities, such as intramural sports, the college newspaper, fraternities or sororities, and/or working a job, but 'the students' remaining free time in college was given over to friendly fun with peers, the bread and butter of college life" (p. 47). These were usually spur-of-the-moment pleasures such as hanging out with friends, going out for pizza, flirting, etc. Moffat found that college students spent about four hours a day practicing informal socializing. For the students, a big part of college life is about autonomy and freedom from adult authority. However, the same cannot be said for student-athletes.

\section{Literature Review}

\section{The Student-Athlete Experience at American Universities}

\section{Regimentation, Stress, and Pressure}

In balancing the demands of university level sports with academic demands, the studentathlete has little time for the informal socializing that Moffatt (1991) described. "Time demands and rigid scheduling are factors of the student-athlete experience that stand out the most" (Jolly, 2007, p. 146). While non-athletes enjoy the autonomy of managing their work-play schedule, much of the student-athletes' schedules are strictly controlled. Not only are there daily afternoon practices that can last two to four hours, many athletes must also attend mandatory tutoring sessions in addition to classes, and their attendance in both is closely monitored. University coaches' well-paid jobs depend on winning, and winning depends on their athletes remaining academically eligible. Thus, coaches maintain a tight rein over their athletes. Also, student-athletes carry a full load (15 hours) because if they fall below that, they lose their National Collegiate Athletic Association (NCAA) eligibility (Meyer, 2005). "These relentless, regimented schedules can take a toll on student-athletes. Because of the highly structured time demands, many of my student-athletes, particularly freshmen, exhibit considerable stress and, in some cases, suffer from depression" (Jolly, 2007, p. 146). In addition to the time demands of practicing, travelling, and competing in their sport while taking a full academic load, there are additional stressors such as "injuries, pressures to win and avoid losses, internal competitions between teammates, media pressures, and sometimes burnout" (Lu et al., 2012, p. 254). 
Approximately $57 \%$ of students at four-year institutions did not return for their sophomore year (Tinto, 1993). Based on 2010 data, nationally only $72 \%$ of fulltime degree/certificate-seeking undergraduates in fall 2009 returned to their institution in their second year and only $44 \%$ of part time students returned (Knapp et al., 2012). In his student-integration theory, Tinto proposed that for students to persist to graduation, they need to be socially and academically integrated with their campus. Relatedly, involvement in school activities is an important predictor of freshmen success (Milem \& Berger, 1997). Certainty about one's major, satisfaction with one's opportunities to interact with faculty, and feeling that faculty were concerned with one's academic success are important predictors of sophomore success (Graunke \& Woosley, 2005). Because of the intense focus on their sport, student-athletes' opportunities to participate in other school activities and engage with faculty are limited, which could impede their academic success.

Because student-athletes have less autonomy and free time, they are less able to enter into "college life," as described by Moffatt (1991). Student-athletes are often segregated from the general student population (Jolly, 2007). They practice, travel, study, and eat together. At schools with athletic dorms, they even live together. As a result, they are less likely to assimilate into campus life and form a successful student identity. Moffatt (1991) found that most of the undergraduate students at Rutgers did not know any of the varsity athletes personally. Most university level athletes report that participating in intercollegiate athletics keeps them from attending to the student side of their lives as much as they would like (Sparent, 1989). A study of 930 student-athletes found that over $60 \%$ of the student-athletes viewed themselves as more of an athlete than a student (Potuto \& O'Hanlon, 2007).

The typical college student also struggles to adjust to college life. The American College Health Association conducts a national college health assessment every year. The 2017 data indicated that within the last 12 months, $87 \%$ of students had felt overwhelmed by all they had to do at some point during the school year, $83 \%$ had felt exhausted, $67 \%$ had felt very sad, $63 \%$ had felt very lonely, $61 \%$ had felt overwhelming anxiety, $52 \%$ had felt things were hopeless, $41 \%$ had felt overwhelming anger, $39 \%$ had felt so depressed it was difficult to function, $12 \%$ had seriously considered suicide, $8 \%$ had intentionally cut, burned, bruised, or otherwise injured themselves, and 2\% had attempted suicide (American College Health Association, 2018). A study of 631 undergraduates found that $47 \%$ had scores on the Center for Epidemiologic Studies Depression Scale that indicated mild to severe symptoms of depression. The eight major stressors identified by the students were: (a) changes in social activities, (b) working with people they don't know, (c) changes in sleeping habits, (d) changes in eating habits, (e) increased class workload, (f) receiving a lower grade than anticipated, $(\mathrm{g})$ being placed in an unfamiliar situation, and $(\mathrm{h})$ changes in living environment (Acharya et al., 2018). Transitioning from life at home and one's high school friends can be difficult. The student-athlete must adjust to the added demands of their sport on top of the demands of college that every student experiences. 


\section{Limited Opportunities to Develop}

In a study of 931 World War II veterans, those who were former high school athletes enjoyed higher-status careers and were more likely to end up in leadership positions, as compared to those who did not play varsity sports. In addition, the ex-athletes exhibited more prosocial behaviors, such as volunteering and donating to charity (Kniffin et al., 2015). However, most high school athletes do not continue their athletic pursuits at the university level where playing for one's school sports team demands a much higher level of commitment.

As mentioned earlier, over $60 \%$ of the student-athletes view themselves as more of an athlete than a student (Potuto \& O'Hanlon, 2007). Additionally, many fellow students and professors hold negative stereotypes about "dumb jocks" who are unqualified for college and are only accepted because of their athletic abilities (Simons et al., 2007). The athletes are aware of these negative stereotypes, which can create self-fulfilling prophesies, or stereotype threats, that lower their academic performance (Dee, 2014; Yopyk \& Prentice, 2005). If student-athletes identify with these negative stereotypes, they will lower their academic expectations for themselves and, subsequently, reduce their academic efforts. Also, if student-athletes believe that their peers perceive them as "dumb jocks," tests and papers can become anxiety producing because poor performances will reinforce their peers' negative stereotypes. Thus, the anxiety brought on by the desire to prove their peers wrong can impair the student-athletes' academic performances.

Student-athletes do struggle academically. Student-athletes exhibit lower critical thinking skills than non-athletes, specifically in the dimensions of open-mindedness, inquisitiveness, and maturity (McBride \& Reed, 1998). A lack of critical thinking skills can negatively impact the student-athletes' professional development. For example, student-athletes who identify strongly and exclusively with their athlete role often fail to explore alternative roles, which leads to delayed career development (Navarro, 2012). Male student-athletes in revenue-producing sports are especially susceptible to this (Murphy et al., 1996).

In addition to negative impacts on the students-athletes' academic performance, as well as cognitive and professional development, participating in college sports can also limit personal development. When compared to non-athletes engaged in extracurricular activities:

[A] higher percentage of athletes reported it was more difficult for them as athletes to take on leadership responsibility, develop new abilities/skills, learn about themselves, learn from their mistakes, take responsibility for others, exercise self-control (basketball and football players only), have close friends, be liked by others for just being themselves, talk about personal problems with others, get to know other students, and speak their mind. (Wrisberg, 1996, p. 396)

It seems that the advantages of participating in college sports comes with a price for many student-athletes as lost opportunities to develop other important aspects of themselves. 


\section{Special Treatment for Athletes in NCAA Division I Revenue-Generating Sports}

Universities want to help their student-athletes succeed on the field and in the classroom. Toward that end, universities invest a great deal in state-of-the-art training facilities and academic centers for athletes (Thamel, 2006). Louisiana State University's \$15 million Cox Communications Academic Center for Student-Athletes is an example, with its 90 computer stations and 14 private computer rooms within its 54,000 square feet of space (Jolly, 2007). Also, the educational support staff in these centers usually report to the athletic director, not academic leaders, whose primary interest is keeping the athletes eligible for competition rather than the development of the whole student (Thamel, 2006). While these kinds of facilities may not be available for the typical student, universities have greatly expanded their academic support services for all students (Kot, 2014).

In addition to the academic centers, some universities have been known to bend the rules for student-athletes. For example, the University of Georgia administrators changed the grades of student-athletes in remedial classes so that they could remain eligible for competition (Schmidt, 1986). More recently, at the University of North Carolina, more than 3,100 students, many of them athletes, were enrolled in nonexistent classes in the African studies department and received credit, usually an A or a B (Lyall, 2014).

For particularly gifted athletes in the revenue-generating sports, special treatment can begin as a high school recruit. Many schools offer package deals, wherein a close associate of the recruit is offered a job with the university or the recruit's friend is also offered a scholarship (Lee, 2010). Many schools have female hostesses to entertain recruits. Because of the competition between schools for top talent, these efforts can sometimes become illegal, such as offering the recruit a bribe or hiring women to sexually engage with them (Lee, 2010).

In order to protect the school's athletic brand, some universities protect athletes who break the law, by attacking a fellow student for example. University officials might persuade campus and local police departments to reduce the charges, provide pro bono legal assistance, intimidate or blame victims, impose weak penalties, and/or provide public relations assistance (Lopiano et al., 2016). Because these actions enable the athletes' violent acts, the odds of them being repeated are increased.

The special treatments mentioned above are usually reserved for athletes in revenuegenerating Division I sports, where sports generate huge profits for the university and huge salaries for the coaches. Branch (2011) argues that the real scandal of big-time college sports is that while the student-athletes generate huge sums of money for their schools, for their coaches, and for private companies, they earn nothing in return for themselves. Southall and Weiler (2014) contend that the student-athlete metaphor created by the NCAA fails to capture the degree of exploitation experienced by the athletes in revenue-generating sports. They suggest neo plantation slavery or company town are better metaphors. Southall and Weiler assert that the NCAA uses the term student-athlete to distract the public and the courts from seeing the athletes as employees. They suggest profit-athlete would be a more appropriate term to capture the relationship between the athletes and the universities. 


\section{The Advantages of Being a Student-Athlete}

In spite of the difficulties of being a student-athlete, a study of student-athletes from 18 Division I schools found that the participants felt that they were having a well-rounded educational experience, that participation in sports was helping their personal development, and that participation in sports would pay off for them, helping them get the job or career they desired. Only $12 \%$ wished they had spent less time on their sport and less than $1 \%$ wished they had not played (Potuto \& O'Hanlon, 2007). Thus, in the minds of the student-athletes, the struggles and stress are worth it.

Although student-athletes may struggle academically, participation in college sports increases these students' motivation to complete college and, subsequently, student-athletes have a higher graduation rate than non-athletes (Gayles, 2009). The regimentation and special tutors do provide emotional and intellectual advantages.

\section{Gender Differences in the Student-Athlete Experience}

One major difference between being a male student-athlete and a female student-athlete is the lack of public acceptance that women receive for participating in sports. For men, being an athlete is the epitome of what it means to be manly. On the other hand, "from an early age, females are reminded that they do not have the tools to be "real athletes"' (Wrisberg, 1996, p. 401). Female student-athletes are less likely to be perceived by others as "jocks," as compared to male studentathletes (Miller et al., 2006). Female athletes also receive inconsistent messages. For example, they may be told by some that they are not athletic enough, and they may be told by others that they are too athletic and not feminine enough. As Steinfeldt et al. (2011) noted:

Female athletes in the United States face the paradoxical challenge of acquiring a degree of muscularity to be successful in their sport, yet they also endure pressure from societal expectations of femininity that often don't conform with the notion of muscularity. (p. 543)

This creates a societal headwind, compared to the societal downwind that athletic men face, that female athletes cannot escape as they negotiate their desires to be muscular for athletic purposes with their desires to meet societal standards of femininity, such as being thin and/or soft, on a daily basis.

There are additional frustrations that female athletes deal with. They are often labelled lesbians regardless of their sexual orientation, they are more likely to experience sexual harassment, and they are more likely to obsess over their weight (Wrisberg, 1996). All of these obstacles can make it more difficult to persevere in the face of hardships, such as injuries or not performing up to expectations.

Given the obstacles that female student-athletes face, it is not surprising that female student-athletes identify less with their athletic selves compared to their male counterparts. Female student-athletes are less likely to describe themselves as a "jock" (Miller et al., 2006). While both male and female student-athletes tend to perceive themselves as athletes first, a larger percentage 
of the male student-athletes feel that way (Potuto \& O'Hanlon, 2007). Relatedly, female studentathletes spend more of their free time on activities unconnected to sports. The men, on the other hand, spend much of their discretionary time watching sports on TV, listening to sports radio, reading about sports, and talking about sports. The women are also more likely to participate in co-curricular activities, such as joining a club related to one's major. And even with their greater involvement in co-curricular activities, the women are more likely to report regret over missed opportunities outside of sports (Potuto \& O'Hanlon, 2007).

Not identifying with one's athletic self is not all bad. This can work in the women's favor, as over identification with one's athlete role negatively impacts career development (Murphy et al., 1996; Navarro, 2012). Also, the more an athlete identifies with the jock identity, the more likely the athlete is to engage in antisocial behaviors. It is usually the male student-athletes who engage in criminal behaviors that create public relations nightmares for coaches and athletic directors (Miller et al., 2006).

An examination of the general student population reveals that women's academic performance surpasses that of men (Ellis et al., 2008). This difference is not caused by differences in intelligence, but by women's higher achievement motivation (Fischer et al., 2013). This gender difference may be even wider in the athletic realm if the male athletes are not as committed to their academic achievements as their female counterparts.

\section{Theoretical Framework}

\section{What Is Organizational Culture?}

There are many definitions of culture. For example, Morgan (2006) defines culture as “the pattern of development reflected in a society's system of knowledge, ideology, values, laws, and day-to-day ritual" (p. 116). Just as societies have cultures, so do organizations, and the definitions of organizational culture mirror those of culture. According to Denison (1996), "organizational culture refers to the deep structure of organizations, which is rooted in the values, beliefs, and assumptions held by organizational members" (p. 624).

Schneider et al. (2013) write that:

organizational culture concerns the implicit values, beliefs, and assumptions that employees infer guide behavior, and they base these inferences on the stories, myths, and socialization experiences they have and the behaviors they observe (especially on the part of leaders) that prove to be useful and promote success. (Schneider et al., 2013, p. 381)

Schein's (2010) definition includes this pattern of shared basic assumptions that are taught to new members as the right way to act within their organization. While the definitions of organizational culture are similar, historically, there have been two very different approaches to studying organizational culture. 


\section{The Qualitative, Anthropological Approach to Understanding Culture}

The concept of culture has a long history in anthropology and cultural anthropologists were the first people to study organizational culture in the 1970s and 1980s. The anthropological approach to studying organizational culture is based on postmodern ideas about social science. These researchers object to the modernist idea that there is an external reality that can be discovered by using scientific methods. Instead, they contend that knowledge is a social construct. Thus, social phenomena, such as organizational culture, can only be understood subjectively, from the perspective of the individuals who are a part of the culture (Hatch \& Cunliffe, 2006). In other words, each organization has its own unique culture that can only be understood through careful study by someone on the inside, such as a participant-observer.

\section{The Quantitative Approach to Understanding Culture}

In contrast to the anthropological idea that an organization is its culture, quantitative researchers believe that organizations have cultures. These researchers are less concerned with each organization's uniqueness and more concerned with how organizations vary on a number of cultural dimensions, and how those dimensions predict organizational effectiveness. Because these researchers take a comparative approach, their favored research tool is the survey (Schneider et al., 2013). An important advantage of the quantitative approach is that researchers can compare different organizational cultures. Because we were interested in comparing academic cultures to athletic cultures, we decided to use a quantitative approach. According to Schneider et al., today, the best known theory for studying organizational cultures is Quinn and Rohrbaugh's (1983) competing values framework. Thus, that is the quantitative approach we settled upon to explore the organizational cultures of the university's academic life and the university's sports life.

\section{Competing Values Framework}

According to Quinn and Rohrbaugh (1983), how an organization defines its effectiveness reveals its values. Within their competing values framework, two dimensions of values are proposed: whether the organization focuses more internally (i.e., on its people and processes) or externally (i.e., on its competitors and systems outside the organization), and whether the organization is more oriented towards flexibility or control. Figure 1 shows how these two value dimensions create four different organizational cultures: clan, adhocracy, market, and/or hierarchy.

An organization with a clan culture is described as an organization that is similar to that of a family unit. Those in clan cultures believe that organizational effectiveness is gained through having employees empowered through their development, involvement, and participation in the company. 


\section{Figure 1}

The Four Cultures of the Competing Values Framework

Flexibility, Discretion, Dynamism

\begin{tabular}{|c|c|c|c|}
\hline \multirow{2}{*}{$\begin{array}{c}\text { Internal Focus on } \\
\text { Integration and Unity }\end{array}$} & \begin{tabular}{l}
$\quad$ Clan \\
\multicolumn{1}{c}{ Culture } \\
Focus on human \\
development and \\
participation
\end{tabular} & $\begin{array}{l}\quad \begin{array}{l}\text { Adhocracy } \\
\quad \text { Culture } \\
\text { Focus on } \\
\text { innovation and } \\
\text { new resources }\end{array} \\
\end{array}$ & \multirow{2}{*}{$\begin{array}{c}\text { External Focus on } \\
\text { Differentiation, } \\
\text { Rivalry }\end{array}$} \\
\hline & \begin{tabular}{l}
\multicolumn{1}{c}{$\begin{array}{c}\text { Hierarchy } \\
\text { Culture }\end{array}$} \\
Focus on control \\
and efficiency
\end{tabular} & $\begin{array}{c}\text { Market Culture } \\
\text { Focus on } \\
\text { customers and } \\
\text { competing } \\
\text { aggressively } \\
\end{array}$ & \\
\hline
\end{tabular}

An organization with an adhocracy culture focuses on the competitive, external environment and consists of specialized units. This type of organization is prepared for frequent changes and embraces change. Adhocracies are focused on generating new products and keeping up with competition through promotion of employee creativity and entrepreneurship to draw in new markets and customers.

Organizations with a market culture are primarily focused on the bottom-line or their profitability. These organizations focus on pushing for increased productivity and reduced costs in order to beat the competition.

Organizations with a hierarchal culture desire consistency and traditionalism. Formal rules and regulations are the center of these organizations. These organizations fit the model of the traditional bureaucracy where every employee has a specific job description and there are detailed policies and procedures to follow.

While each organization may have a dominant culture, each organization also displays some of the characteristics of the four culture types (Cameron \& Quinn, 2011). This is an important point when understanding and assessing an organization's culture across four dimensions. While clan cultures enjoy greater employee morale, market cultures greater profit, adhocracy cultures greater innovation, and hierarchical cultures greater efficiency, organizations with balanced cultures enjoy greater success across a broad range of success criteria (Hartnell et al., 2011). Thus, another advantage of using this framework is to point out how coaches and campus leaders might improve their respective organizational cultures. 


\section{Organizational Subcultures}

The official organizational culture includes aspects that are considered more formal for the organization. These formalities can include the mission statement, as well as the written rules and regulations that may be found in an employee handbook. Establishment of the official organizational culture is chiefly put in place by top management and is what everyone outside of the organization can see at a quick glance (Jermier et al., 1991). Jermier et al. explain that subcultures are created out of employees challenging or lacking acceptance of the official culture. Many subcultures may modify and replace the official culture while at the same time coexisting with little resistance. It is important to understand that while the overall culture dictates the broad set of organizational beliefs and values, each subculture, which can be made up of teams, divisions, or hierarchical levels, has its own unique beliefs, values, and rules that define it (Cameron \& Quinn 2006; Jermier et al., 1991). One of the goals of this study is to explore a university's academic and sports subcultures. A better understanding of culture can help campus leaders diagnose whether their team or department's culture is out of balance and create plans for cultural change.

\section{Research Questions}

Given the differences between the college life of the general student population and the college life of student-athletes, we chose to investigate how the organizational cultures of the students' academic departments differed from the organizational cultures of the student-athletes' sports teams. In other words, is the university's sports world a separate subculture? Also, given the differences between the experiences of male and female athletes, and male and female students in general, we wanted to explore the organizational cultures of the men's and women's teams and the organizational cultures of university schools that were predominantly more male or female, such as the School of Business and the Teachers College. We were curious whether culture is more a product of gender or of activities. For example, would women's sports teams resemble the female dominated Teachers College and men's sports teams the male dominated School of Business? Or would there be an athletic culture and an academic culture? The answer to these questions might provide campus leaders, such as coaches and faculty, with insights into their leadership styles. Also, the comparisons might provide these leaders with different models of leadership to explore and emulate.

Research Question 1a. Are the organizational cultures of university sports teams different from the organizational cultures of university academic departments?

Research Question 1b. Are students more satisfied with their sport or with their major?

Research Question 1c. Is satisfaction with one's sport or with one's major predicted with the same organizational culture variables? For example, previous research indicates that clan cultures predict higher satisfaction levels in the job (Lund, 2003). Will the same be true for sports teams and academic departments at a university?

Research Question 2a. Do men and women differ in how they perceive the organizational cultures of their sports teams and their academic departments? 
Research Question $2 \boldsymbol{b}$. Do men and women differ in their satisfaction with their sport or major?

Research Question 2c. Do men and women differ in what organizational culture variables predict their satisfaction with their sport or major?

\section{Participants}

\section{Method}

There were two groups of participants in this study. One group was composed of 259 students in upper-level classes in a variety of different schools and departments at a regional state university. The focus was on junior and senior classes because upper classmen have a better feel for their department's culture. Fifty-eight participants were from the School of Business, 100 were from Liberal Arts and Sciences, and 101 were from the Teachers College. While $67 \%$ of these participants were women, the School of Business had a higher percentage of male students $(57 \%)$ than either Liberal Arts and Sciences (22\%) or the Teachers College (29\%).

The other group of participants in this study were 230 student-athletes from the same regional state university representing eight teams. One hundred fifty-seven were men and 73 were women. The data for the first group were collected a year before the data for the second group. These were initially two different studies at the same university using the same instruments. The authors realized that their studies would be more interesting if they combined their findings.

\section{Instruments}

\section{Organizational Culture Assessment Instrument (OCAI)}

This measure is based on the Competing Values Framework developed by Cameron and Quinn (2006). It is used to identify the cultural profile of an organization. The OCAI assesses six key dimensions of organizational culture: (a) dominant characteristics, (b) organizational leadership, (c) management of employees, (d) organization glue, (e) strategic emphases, and (f) criteria of success. Examples of the items under the dominant characteristics dimension of an organization include: "The organization is a very personal place. It is like an extended family. People seem to share a lot of themselves," (clan); "The organization is a very dynamic entrepreneurial place. People are willing to stick their necks out and take risks," (adhocracy); "The organization is very results oriented. A major concern is with getting the job done. People are very competitive and achievement oriented," (market); and "The organization is a very controlled and structured place. Formal procedures generally govern what people do," (hierarchy). Participants were asked to split their organization $100 \%$ between the four choices for each cultural dimension. For example, on the dominant characteristics dimension of organizational culture, a participant might decide that their organization is $40 \%$ clan, $10 \%$ adhocracy, $30 \%$ market, and $20 \%$ hierarchy.

Cronbach alpha coefficients assessing internal consistency ranged from .71 to .79 in a study conducted by Quinn and Spreitzer (1991). In our study of 259 students rating the organizational culture of their academic departments, the alpha coefficients ranged from .81 for the clan culture, .75 for market culture, .71 for hierarchy culture, to .56 for adhocracy culture for the 259 students. 
On the other hand, for the 230 student-athletes rating the organizational culture of their sports teams, the alpha coefficients ranged from .68 for the clan culture, .70 for market culture, .53 for hierarchy culture, to .62 for adhocracy culture. The internal consistency of the four organizational culture scales were lower for our two student samples than the research on business organizations. This suggests that the students might have struggled a bit translating the terms from a business environment to an academic or sports environment.

\section{Student Satisfaction with Major}

To measure this variable, we used an adaptation of the global job satisfaction scale developed by Quinn and Shepard (1974) and modified by Pond and Geyer (1991). It is a six-item, self-report measure with a five-point Likert scale. A sample item is, "If you had to decide all over again whether to choose the major you now have, what would you decide?" Each question has its own scale anchors. For example, the anchors for the sample item above ranged from 1 (definitely not choose this major) to 5 (definitely choose this major). Another item is "All things considered, how satisfied are you with your current major?" The anchors for this item range from 1 (not at all satisfied) to 5 (completely satisfied). For the 259 students in this study, Cronbach's alpha for assessing the internal consistency of this scale was .82 .

\section{Student-Athlete Satisfaction with Sport}

To measure this variable, we again used an adaptation of Quinn and Shepard's (1974) global job satisfaction scale that had been modified by Pond and Geyer (1991). Two sample items are, "If you had to decide all over again whether to choose the sport you are in now, what would you decide?" and "All things considered, how satisfied are you with your sport?" For the 159 student-athletes who completed this instrument, Cronbach's alpha for assessing the internal consistency of this scale was .83 .

\section{Demographics}

In addition to the main study variables, we collected data on gender, sports team, and the college/school of the students' major.

\section{Procedures}

Before collecting any data, we obtained approval from the university's Institutional Review Board. To collect the student data, we first contacted the university's institutional research analyst to obtain data on the largest departments within this institution. Our approach was to identify the largest undergraduate departments in the university's three colleges/schools. After that we contacted, via email, the professors teaching the largest junior and senior level classes in those departments, asking them if we could come to their classes and survey their students. We then visited the classes and administered the surveys during class. Each student was also given an informed consent form to complete prior to beginning the survey. Each class was given ten minutes to complete the informed consent forms and the surveys. These data were collected during the spring of 2015. 
To collect the student-athlete data, we first contacted the university's head football coach and asked him if we could collect data during a team meeting. After he agreed, we administered the surveys during a team meeting. Each player was given an informed consent form to complete first and then the survey. These data were collected during the spring of 2016. The data for the seven additional sports teams were collected in a similar fashion during the fall of 2016.

\section{Results}

\section{Student Compared to Athlete Perceptions of Organizational Culture}

The first research question was whether the organizational cultures of the university's sports teams differed from the organizational cultures of the university's academic departments. When we asked the students to describe the organizational culture of their academic departments, the university was predominantly seen as having a clan culture. However, when we asked the student-athletes to describe the organizational culture of their sports teams, a more balanced culture emerged with the clan and market dimensions as the highest. As can be seen in Table 1, the biggest difference (8.1 points) was seen on the market dimension $(t(488)=10.1, p<.001)$ where the sports culture was more market based than the academic culture. The academic culture, on the other hand, was higher on the clan dimension (5.4 points) $(t(488)=-5.5, p<.001)$ and the hierarchy dimension $(2.0$ points $)(t(488)=-2.8, p<.01)$. Only the adhocracy dimension showed no significant difference (0.6 point differential) $(t(488)=-1.1, p>.05)$ between academic departments and sports teams. Because Table 1 holds a lot of information, we depicted the differences between the sports and academic cultures in Figure 2 to help the reader see the differences between the two types of cultures.

Our second research question was whether students are more satisfied with their sport or with their major. We found that the athletes were slightly more satisfied with their sport than the students were with their major $(t(416)=4.20, p<.001)$, as seen in Table 1 . 
Journal of Higher Education Athletics \& Innovation

Volume 1, Issue 7

Table 1

Descriptive Statistics for the Athletes and Students on Each Cultural Dimension and Satisfaction

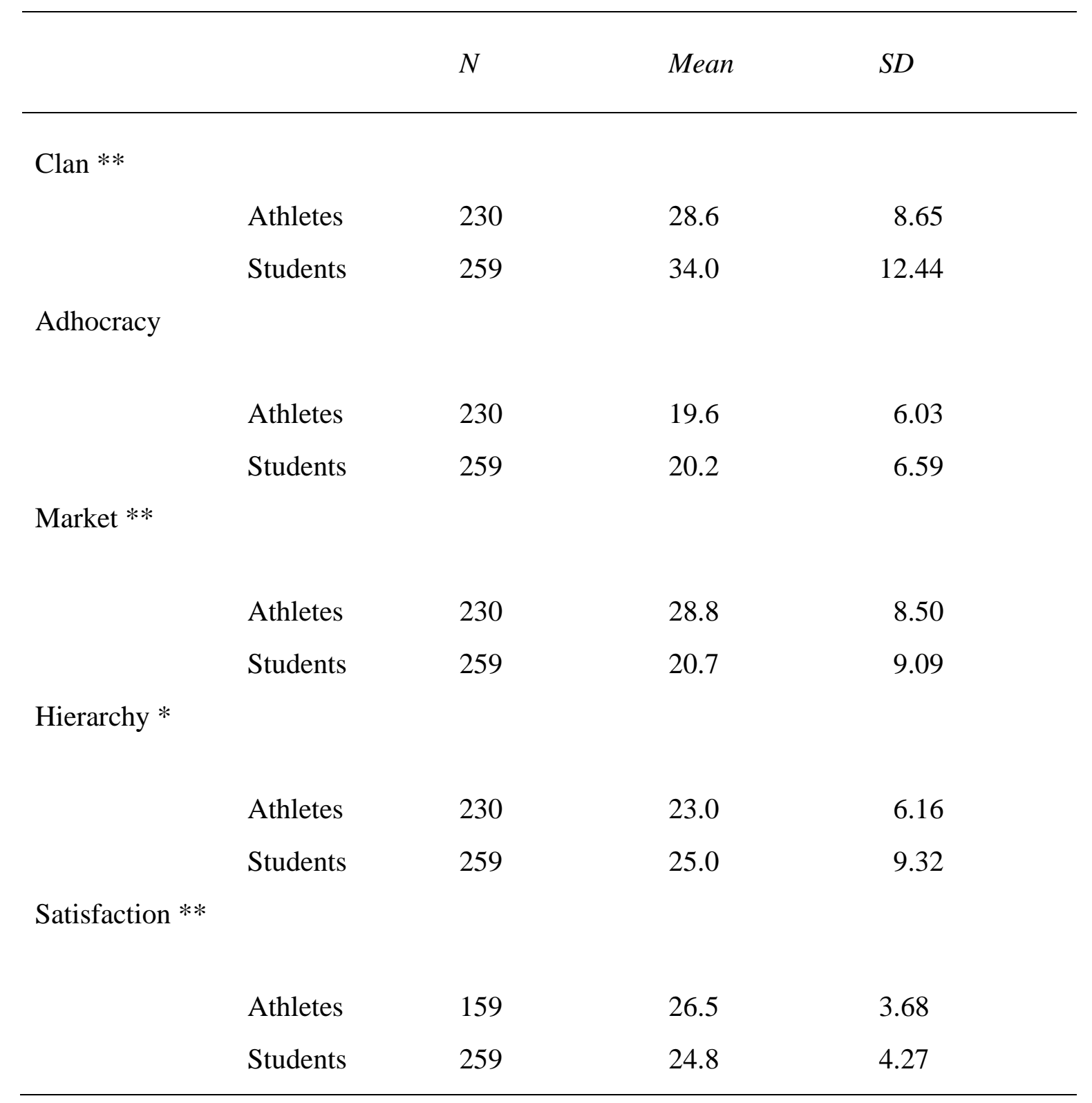

* Significant at the .01 level

** Significant at the .001 level

Note. There were fewer athletes for the Satisfaction variable because the football player data were collected a semester earlier and this variable was not measured in that study. 
Figure 2

How the University's Organizational Culture Is Perceived by Its Athletes and Students

CLAN

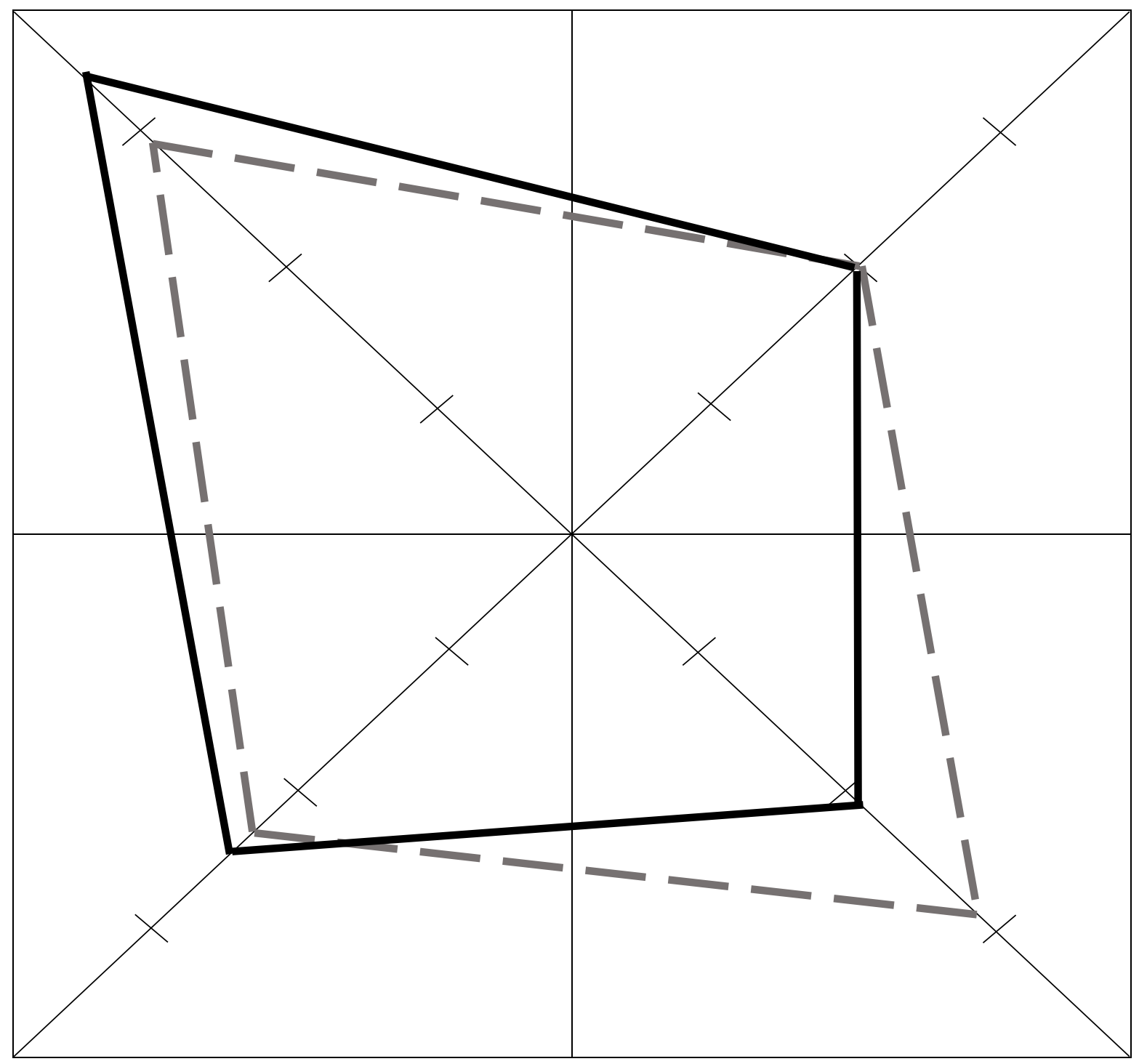

HIERARCHY
ADHOCRACRY

MARKET

Organizational Culture of Sports Teams

Organizational Culture of Academic Departments 
Our third research question was whether satisfaction with one's sport or with one's major was predicted with the same organizational culture variables. As can be seen in Table 2, the students were more satisfied when they perceived the organizational cultures of their academic departments to be high on the clan dimension and low on the market and hierarchy dimensions. The satisfaction of the athletes, on the other hand, were less dependent on cultural dimensions.

\section{The Role of Gender}

We had three research questions that explored the role of gender. The first question was whether men and women differ in how they perceive the organizational cultures of their sports teams and academic departments. We first explored the clan dimension of organizational culture. With a $2 \times 2$ ANOVA we found no interaction, just a main effect for sports vs. academic (that was reported in the previous section) and a main effect for gender $(F(1,485)=10.30, p<.001)$. As Table 3 shows, female sports teams are slightly more clannish than male sports teams and female students rate their academic departments as more clannish than the male students.

For adhocracy scores, the interaction of university experience (sports vs. academic) and gender was not significant, but there was a main effect for gender $(F(1,485)=4.04, p<.05)$. As Table 3 shows, the women rated their sports teams and academic departments as slightly lower on adhocracy than did the men.

On the market dimension of organizational culture, the interaction of university experience (sports vs. academic) and gender was not significant and there was not a main effect for gender $(F$ $(1,485)=2.13, p>.05)$. As Table 3 shows, the athletes, men and women, rated their sports teams fairly high on market, while the students rated their academic departments lower on market.

Finally, for the hierarchy dimension of organizational culture, the interaction of university experience (sports vs. academic) and gender was not significant and there was not a main effect for gender $(F(1,485)=1.22, p>.05)$. As Table 3 shows, the athletes, men and women, rated their sports teams higher on hierarchy than the students rated their academic departments.

The second gender related research question was whether men and women differ in their satisfaction with their sport or major. With a 2 × 2 ANOVA, we examined the interaction of university experience (sports vs. academic) and gender on satisfaction. The interaction was significant $(F(1,413)=5.22, p<.05)$. As shown in Table 3 , satisfaction with their sport was about the same for male and female athletes, but satisfaction with their major was lower for the male students compared to the female students. 
Journal of Higher Education Athletics \& Innovation

Volume 1, Issue 7

Table 2

Correlations between Cultural Dimensions and Satisfaction for Athletes and Students

\begin{tabular}{lcccc}
\hline & Clan & Adhocracy & Market & Hierarchy \\
\hline Athletes $(\mathrm{N}=159)$ & -0.01 & .10 & -0.08 & .02 \\
Students $(\mathrm{N}=259)$ & $.29 * *$ & -0.01 & $-0.19 *$ & $-0.19 *$ \\
\hline $\begin{array}{l}* \\
* * .01\end{array}$ & & & & \\
$*<<.001$ & & &
\end{tabular}




\section{Table 3}

Descriptive Statistics for the Athletes and Students on Each Cultural Dimension and Satisfaction by Gender

\begin{tabular}{|c|c|c|c|c|}
\hline & & $N$ & Mean & $S D$ \\
\hline \multirow[t]{4}{*}{ Clan } & Male Athletes & 157 & 28.1 & 8.79 \\
\hline & Female Athletes & 73 & 29.9 & 8.26 \\
\hline & Male Students & 84 & 30.7 & 11.66 \\
\hline & Female Students & 175 & 35.6 & 12.53 \\
\hline \multirow[t]{4}{*}{ Adhocracy } & Male Athletes & 157 & 20.1 & 6.09 \\
\hline & Female Athletes & 73 & 18.2 & 5.73 \\
\hline & Male Students & 84 & 20.6 & 6.06 \\
\hline & Female Students & 175 & 20.0 & 6.84 \\
\hline \multirow[t]{4}{*}{ Market } & Male Athletes & 157 & 28.7 & 9.22 \\
\hline & Female Athletes & 73 & 28.9 & 6.80 \\
\hline & Male Students & 84 & 22.6 & 9.29 \\
\hline & Female Students & 175 & 19.8 & 8.88 \\
\hline \multirow[t]{4}{*}{ Hierarchy } & Male Athletes & 157 & 28.7 & 6.13 \\
\hline & Female Athletes & 73 & 28.9 & 6.31 \\
\hline & Male Students & 84 & 26.1 & 9.81 \\
\hline & Female Students & 175 & 24.5 & 9.06 \\
\hline \multirow[t]{4}{*}{ Satisfaction } & Male Athletes & 86 & 26.8 & 4.11 \\
\hline & Female Athletes & 72 & 26.2 & 3.11 \\
\hline & Male Students & 84 & 23.9 & 4.47 \\
\hline & Female Students & 175 & 25.2 & 4.12 \\
\hline
\end{tabular}


The third question was whether men and women differ in what organizational culture variables predict their satisfaction with their sport or major. As we delved deeper into the data, we found that gender played an important role in explaining the differences between students and athletes. The female athletes' relationship with clan culture was unlike the other three groups' positive relationship, as can be seen in Table 4 . The correlation between clan culture and satisfaction was highest for the female students $(r(175)=.31, p<.001)$, followed by the male students $(r(84)=.18, p>.05)$ and the male athletes $(r(86)=.12, p>.05)$. However, the correlation between the two variables was negative for the female athletes $(r(72)=-0.15, p>.05)$. Using a Fisher's $r$ to $Z$ transformation, the difference between the female students' correlation and the female athletes' correlation was significant $(Z=3.31, p<.001)$. The female athletes' negative correlation was also significantly different from the male students' correlation $(Z=2.03, p<.05)$ as well, but not the male athletes' correlation $(Z=1.67, p=.09)$.

As with clan culture, the female athletes' relationship with market culture was also unlike the other three groups' relationship, as can be seen in Table 4. The market culture is the opposite of the clan culture, so it was not surprising to find that market culture was the best predictor of sports satisfaction for the female athletes $(r(72)=.17, p>.05)$. For the other three groups, however, market culture was inversely related to satisfaction, especially for the female students $(r$ $(175)=-0.26, p<.001)$ and the male athletes $(r(86)=-0.22, p<.05)$, but not as much for the male students $(r(84)=-0.03, p>.05)$. Using a Fisher's $r$ to $\mathrm{Z}$ transformation, the difference between the female students' correlation and the female athletes' correlation was significant $(Z=3.07, p<$ $.01)$. The female athletes' positive correlation was also significantly different from the male athletes' correlation $(Z=2.43, p<.05)$ as well, but not the male students' correlation $(Z=1.23, p$ $>.05)$.

As seen in Table 4, adhocracy was not a strong predictor of satisfaction for any group, while hierarchy was inversely related to academic satisfaction, but unrelated to sports satisfaction.

\section{Sports Teams Across the University}

While not one of our research questions, we wondered whether there were sports subcultures. The organizational culture profiles for the eight teams depicted in Table 5 suggest that the teams are culturally different. It is hard to make generalizations about gender. Some female teams are highly clannish, i.e., softball and volleyball, while women's track and basketball are less so. However, the women's basketball team is the most successful team on campus. It also has the highest satisfaction score, as seen in Table 5. Its culture is more market than clan. The volleyball team, on the other hand, has the lowest satisfaction score and it is more clan than market. Those two teams may be driving the negative correlation between clan and satisfaction, as well as the positive correlation between market and satisfaction for female athletes. 
Journal of Higher Education Athletics \& Innovation

Volume 1, Issue 7

\section{Table 4}

Correlations between Cultural Dimensions and Satisfaction for Athletes and Students by Gender

\begin{tabular}{lcccc}
\hline & Clan & Adhocracy & Market & Hierarchy \\
& & & & \\
Athletes & & & & \\
$\quad$ Men $(\mathrm{N}=86)$ & .12 & .11 & $-0.22^{*}$ & .06 \\
$\quad$ Women $(\mathrm{N}=72)$ & -0.15 & .05 & .17 & -0.03 \\
Students & & & & \\
$\quad$ Men $(\mathrm{N}=84)$ & .18 & 0.02 & -0.03 & -0.20 \\
$\quad$ Women $(\mathrm{N}=175)$ & $.31^{* *}$ & -0.01 & $-0.26^{* *}$ & $-0.17^{*}$ \\
\hline$* \quad p<.05$ & & & & \\
$* * p<.001$ & & & &
\end{tabular}

Table 5

Organizational Cultural Differences in Sports Teams

\begin{tabular}{|c|c|c|c|c|c|}
\hline & Clan & Adhocracy & Market & Hierarchy & Satisfaction \\
\hline Football $(\mathrm{N}=70)$ & 29.2 & 20.3 & 26.7 & 24.0 & N/A \\
\hline Men's Baseball $(\mathrm{N}=38)$ & 26.8 & 19.6 & 32.2 & 21.4 & 28.0 \\
\hline Men's Track $(\mathrm{N}=34)$ & 27.4 & 20.3 & 29.6 & 22.7 & 26.0 \\
\hline Men's Bball $(\mathrm{N}=15)$ & 28.0 & 20.7 & 27.2 & 24.1 & 25.6 \\
\hline Women's Track $(\mathrm{N}=35)$ & 27.7 & 19.8 & 29.0 & 23.5 & 26.1 \\
\hline Women's Softball $(\mathrm{N}=16)$ & 33.9 & 18.3 & 26.5 & 21.3 & 26.7 \\
\hline Volleyball $(\mathrm{N}=12)$ & 33.6 & 16.4 & 26.8 & 23.2 & 24.0 \\
\hline Women's Bball $(\mathrm{N}=10)$ & 26.8 & 14.7 & 35.5 & 23.0 & 28.1 \\
\hline
\end{tabular}




\section{Academic Departments Across the University}

We also wondered whether there were academic sub-cultures. The organizational culture profiles depicted in Table 6 suggest that the university's three colleges/schools are culturally different. There was a significant main effect for college/school $(F(2,256)=14.95, p<.001)$ on the clan dimension. Based upon Tukey's HSD post hoc test, the clan culture was significantly lower among students in the Business School compared to Liberal Arts \& Sciences, $p<.001$, and compared to the Teachers College, $p<.001$.

As the market culture is the opposite of the clan culture, we found the exact opposite results for this dimension $(F(2,256)=14.27, p<.001)$. Based upon Tukey's HSD post hoc test, the market culture was significantly higher among students in the Business School compared to Liberal Arts \& Sciences, $p<.01$, and compared to the Teachers College, $p<.001$. In addition, the market culture was significantly higher among students in the Liberal Arts \& Sciences compared to the Teachers College, $p<.05$.

No significant differences emerged between the three colleges/schools on adhocracy $(F(2$, $256)=.20, p>.05)$ or hierarchy $(F(2,256)=2.72, p=.07)$. There were also no differences in satisfaction with one's major $(F(2,256)=.83, p>.05)$.

\section{Discussion}

\section{Athletic Cultures Are Different from Most Academic Cultures}

In general, we found that academic cultures were more clannish and less market driven than sports cultures. This was not a surprising result, as life is much more regimented and demanding for student-athletes (Jolly, 2007). Also, unlike college professors, college coaches' job security depends on how well their athletes perform. Thus, student-athletes are under great pressure to perform (Lu et al., 2012), which creates a more market driven culture.

The non-athlete students in our study were more satisfied with their academic department when they perceived the organizational culture to be higher on the clan dimension and lower on the market and hierarchy dimensions. This result was not surprising, as this is what is seen in corporate life. Research on clan cultures has shown significantly higher levels of job satisfaction than both market and hierarchy culture in a survey of marketing professionals (Lund, 2003). Additionally, clan cultures are strongly correlated with positive employee attitudes (Hartnell et al., 2011). An investigation of a college found that clan cultures were strongly associated with high morale, satisfaction with the leaders, trust, and a sense of equity among the organization's members (Zammuto \& Krakower, 1991). 


\section{Table 6}

Satisfaction and Organizational Cultural Differences in Academic Departments between Schools

\begin{tabular}{lcccccc}
\hline & \multicolumn{2}{c}{ Business School } & \multicolumn{2}{c}{ L.A. \& Sciences } & \multicolumn{2}{c}{ Teachers College } \\
& \multicolumn{2}{c}{$(N=58)$} & \multicolumn{2}{c}{$(N=100)$} & \multicolumn{2}{c}{$(N=101)$} \\
& $M$ & $S D$ & $M$ & $S D$ & & \\
& & & & & & \\
& 27.1 & 9.55 & 34.3 & 13.11 & 37.8 & 11.64 \\
Clan & 20.0 & 6.74 & 20.5 & 6.48 & 20.0 & 6.65 \\
Adhocracy & 25.3 & 8.05 & 21.1 & 9.66 & 17.8 & 7.90 \\
Market & 27.5 & 9.65 & 24.2 & 9.26 & 24.5 & 9.02 \\
Hierarchy & 24.2 & 4.63 & 24.9 & 3.93 & 25.0 & 4.39 \\
Satisfaction & & & & & & \\
\hline
\end{tabular}

We were surprised to find that the satisfaction of the student-athletes with their sports teams was unrelated to the organizational cultural dimensions of their teams. While there has been a great deal of research showing the relationship between clan cultures and job satisfaction, in a 2010 study of the relationships between organizational culture dimensions and job satisfaction in Russian businesses, Zavyalova and Kucherov (2010) found a more complex relationship. While clan cultures satisfy employees' need for respect, market cultures create conditions for the satisfaction of self-affirmation needs through business success, adhocracy cultures satisfy selfactualization needs, and hierarchy cultures satisfy safety needs. Relatedly, Hampton and Hampton (2004) found that a market orientation can lead to job satisfaction when it promotes greater professionalism and organizational success. It seems more research is needed on the relationship between cultural dimensions and job satisfaction.

While the sports cultures were less clannish, and clan culture is usually a predictor of job satisfaction (Hartnell et al., 2011; Lund, 2003), we found that the student-athletes were slightly more satisfied with their sport team than the students were with their academic department. One explanation for this could be cognitive dissonance. Cognitive dissonance begins when someone engages in a behavior that either threatens their self-esteem or is inconsistent with their idea of themselves (Stone \& Cooper, 2001). The two dissonant cognitions, "I did X" and "that behavior is inconsistent with who I am," are discomforting. To resolve the dissonance, an individual may create a new cognition to justify the behavior. For example, if someone cheats on a test, they may create a belief that most of their classmates cheated as well so that they do not feel bad about themselves anymore. Research has shown that increased task difficulty can induce participants to rate the task as more valuable, meaningful, and interesting (Aronson \& Mills, 1959; Gerard \& 
Mathewson, 1966; Rosenfeld et al., 1984). As mentioned previously, student-athletes' lives tend to be more regimented, demanding, and stressful (Jolly, 2007; Lu et al., 2012). The dissonant cognitions might be "I am allowing myself to be treated poorly" and "I like myself." The new cognition might be "My sport is very important to me." Thus, undergoing the punishing tasks of one's sport becomes consistent with liking oneself, "I am doing this because it is important to me." It would be interesting to see whether an increase in workload on the academic side might foment greater student commitment and satisfaction.

Social identity theory might provide another possible explanation for why the studentathletes were slightly more satisfied with their sport team than the students were with their academic department. In his study of undergraduate medical students in England, Lovell (2015) pointed out that the medical students tended to form into a separate community (Weaver et al., 2011) and that played a large role in the students' identity development (Monrouxe, 2010). Lovell (2015) identified four reasons for the medical students' strong identity with their group:

The first is enforced isolation, and describes the geographical and institutional separation of medics from other undergraduates.

The second is self-isolation and refers to the tendency of medical students to form exclusive social groups to maximize opportunities to "decompress", obtain social constancy and facilitate horizontal learning.

The third concerns the supportive network, wherein the medical community serves to provide its members with mutual support.

The final theme refers to judging self and others, and describes both the respectful and critical ways in which students perceive themselves and their peers. These themes influence one another in an ongoing dynamic fashion, and grant insight into the establishment and maintenance of a cohesive medical community. (p. 1016)

We see these four themes mirrored in the lives of student-athletes. While students in the same major take many of the same classes and work together on projects occasionally, they do not spend as much time together as student-athletes who train daily, eat together, travel, and compete in a tight knit group. Research indicates that group members tend to perceive the followers of their group as evincing effective follower behavior, such as displaying enthusiasm, hard work, and good citizenship, while they tend to perceive the followers of out groups as evincing less effective follower behaviors, such as conformity, incompetence, and insubordination (Steffens et al., 2018). Perhaps the student-athletes' satisfaction with their teams comes, in part, from the strong sense of identity the team provides and the comradery with teammates.

As seen in Table 6, the organizational culture of the Business School was less clannish than the organizational cultures of the School of Liberal Arts and Sciences and the Teachers College. We wondered whether this might be due to the gender makeup of the three schools/colleges. Across the three schools/colleges, $43 \%$ of the participants from the Business School were women, $78 \%$ of the participants from the School of Liberal Arts and Sciences were women, and 71\% of the participants from the Teachers College were women. In a synthesis of 162 studies of gender 
differences in leadership style, it was found that some leadership styles are gender-specific. Women tended to be interpersonally oriented and led more democratically than their male counterparts, while men tended to be more autocratic and task-oriented (Eagly \& Carli, 2003). Perhaps female students prefer a clan-oriented culture and male students prefer more of a market culture. Because men and women lead differently, they create different cultures. Each type of culture has advantages and disadvantages, which is why the balanced culture often correlates best with organizational performance (Hartnell et al., 2011). Subsequently, men can learn leadership lessons from women. As men dominate the leadership positions in most organizations, women already have many opportunities to learn leadership lessons from men.

\section{The Nature of Female Athletic Culture}

We found that women are more likely to describe their academic departments and their sports teams as clannish compared to the men. This was not surprising, since peer groups composed of boys tend to have more members and more casual relationships. Peer groups composed of girls, on the other hand, tend to have fewer members and closer, more intimate friendships (Maccoby, 1990; 1998). Thus, women tend to create more clannish cultures when they intermingle. This might explain why the academic departments in the Business School were less clannish than the academic departments in the Teachers College and the School of Liberal Arts and Sciences. The Business School has more male students and faculty than female students and faculty, while the other two colleges are the reverse. Perhaps gender plays a role in defining an organization's culture.

Research on preferred leadership styles have found that female athletes prefer more democratic styles, while male athletes prefer more autocratic styles (Beam et al., 2004; Chelladurai \& Arnott, 1985; Terry, 1984). The leader's role in a clan culture is to mentor subordinates and facilitate group problem solving (Denison et al., 1995). A democratic leader will perform better than an autocratic leader at these tasks. On the other hand, the leader's role in a market culture is to direct subordinates to ensure results (Denison et al., 1995). An autocratic leader will perform better at these tasks. Thus, female athletes may respond better to coaches who promote clan cultures, while male athletes may respond better to coaches who promote market cultures.

Given the female preference for clan culture and democratic leadership, we were surprised by the negative correlation between clan culture and satisfaction with one's sport for the female athletes. The opposite result was found for all the other participants. Relatedly, the correlation between market culture and satisfaction with one's sport was positive for the female athletes, but negative for all others. While the female athletes thrived within market cultures and were less happy within clan cultures, the female athletes' teams tended to be more clan and less market than the male athletes' team cultures. Why do the female athletes' experiences diverge from everyone else's?

One possible explanation for the female student-athletes' preference for market cultures is the presence of male coaches. While all of the men's teams have male coaches, two of the four women's teams have male coaches. Research on gender/self-disclosure relationships has revealed that female disclosers usually prefer a female target, although there are a number of moderating variables (Rosenfeld et al., 1979). However, this general conclusion may not hold in the sports 
world. A study of 395 female high school athletes found no difference in the amount of disclosure the athletes made to male or female coaches. Also, there was less disclosure to the girls' coaches of either gender than to the girls' parents and friends. However, the female athletes did disclose differ kinds of information to male and female coaches. Their self-disclosure to the male coaches was generally more impersonal and primarily dealt with school matters. The athletes were more comfortable disclosing more intimate topics to their female coaches, such as embarrassing situations (Officer \& Rosenfeld, 1985). Thus, women playing for a male coach may prefer a more business oriented, less disclosing, clannish culture. Another reason female athletes may prefer a less clannish culture with a male coach is because of the vulnerability of young, female athletes to harassment and abuse (Tomlinson \& Yorganci, 1997).

A meta-analysis of team cohesion and performance found that the relationship between team cohesion and team performance is significantly higher for female teams than for male teams (Carron et al., 2002). The authors concluded, "From a performance perspective, it would seem especially important for coaches and applied sport psychologists to strive to maintain high cohesiveness and prevent team conflict in female teams" (p. 183). That, however, may be easier said than done, as women are more likely than men to use social manipulations to get back at team members with whom they are angry, such as insulting comments about one's private life, false rumors, insinuations without accusations, backbiting, insinuative negative glances, the silent treatment, and do-not-speak-to-me behaviors (Bjorkqvist et al., 1994). Because social manipulations are difficult to conceal, the recipient can readily identify their tormentor. These social manipulations can sow more discord within a team. Given the fact that female teams tend to be more cohesive and intimately connected, the use of social manipulations could be doubly painful. Perhaps female athletes prefer less clannish environments and a more impersonal approach to avoid damaging conflicts and to maintain team cohesion.

\section{Limitations}

The main threat to this study's internal validity was its correlational design. No causal relationships could be revealed between cultural dimensions and satisfaction. The main threat to this study's external validity was its convenient sample. By gathering data from a single university, this study's generalizability to other educational institutions is severely limited.

The time and setting during which data was collected could have possibly led to a confounding variable. Many of the participants that were athletes had to take both the Organizational Culture Assessment Instrument (OCAI) and satisfaction survey during their practice and/or conditioning times, with almost half of the sports being in season. The setting could have possibly rushed the athletes to poorly read the questions and answer quickly on both instruments, but there is no clear evidence to indicate this transpired. Also, we neglected to include the satisfaction measure with the football players because their data were collected a semester earlier before we had decided to add the satisfaction measure. Future researchers should look at a controlled setting for participants to take the survey in.

A number of the participants had difficulty filling out the OCAI. Those participants were confused by the point system and some had difficulty distributing the points between the four options. Some of the surveys were incomplete due to the participants' frustration with the survey. 
Future researchers may want to provide assistance to participants who struggle with the mathematical component of the OCAI.

\section{Practical Implications for Coaches and Campus Leaders}

As mentioned previously, the male athletic experience in college differs from the female athletic experience. Thus, to be effective, a coach might want to account for differences in gender and organizational culture in their approach to male and female athletes. In our study we found that satisfaction with one's sports team was related to more of a clan and less of a market culture for the male student-athletes. These preferences could be related to how many male coaches approach their job. In a study of male and female track and field athletes, the male coaches were found to use an authoritarian leadership style (Tomlinson \& Yorganci, 1997). A study of elite female soccer players found that the male coaches were portrayed as having a stricter style of interaction, while the female coaches communicated more effectively and were described as "better psychologists" (Fasting \& Pfister, 2000). In other words, the female soccer players described their female coaches as possessing greater insight into their experiences, engaging in more nurturing behaviors, and taking the athletes and their sport more seriously than male coaches of female athletes sometimes do. Male athletes are more comfortable with authoritarian leadership than female athletes, who prefer a more democratic coaching style. Women, more than the men, want to be involved in decision making (Beam et al., 2004; Horn, 1992). However, there are limits to the effectiveness of authoritarian leadership in coaching young men. Male athletes prefer supportive leaders who satisfy their interpersonal needs (Beam et al., 2004). A balanced culture might be what coaches should aspire to.

In coaching female athletes, a balanced culture may also be the ideal, but with some nuanced differences. While female athletes desire involvement in decision making (Beam et al., 2004; Horn, 1992), they may not want to disclose intimate matters to male coaches (Officer \& Rosenfeld, 1985). Carron et al. (2002) stressed the importance of maintaining high cohesiveness in reducing team conflict in female teams. A study of elite female basketball and handball teams found that the most effective coaches focused on group integrating tasks, while less effective coaches used interpersonal competition to promote rivalry among team members, which decreased social cohesion (Heuz'e et al., 2006).

Adding another wrinkle, leadership preferences depend somewhat on the sport (Beam et al., 2004). Both female and male athletes in individual sports, such as track and field, prefer more democratic, supportive leadership than athletes in interdependent team sports, where a slightly more authoritarian, market-oriented approach may be appropriate. Thus, it is difficult to make sweeping generalizations about how to coach women or how to coach men because there are a number of situational factors, in addition to the subordinates' gender, that influence leader effectiveness.

Organizations with balanced cultures enjoy greater success across a broad range of success criteria (Hartnell et al., 2011). One reason for this is that leaders of balanced cultures display what Denison et al. (1995) call behavioral flexibility. The development of each type of culture demands different leadership skills. For example, building a clan culture requires mentoring and facilitating, building a market culture requires directing and producing, building an adhocracy culture requires 
innovating and brokering, building a hierarchy culture requires monitoring and coordinating. Effective leaders have the behavioral flexibility to play multiple roles and hold the creative tension of developing subordinates while at the same time directing them; of innovating while at the same time building reliable, consistent performance. The coaches in this study seemed to intuitively move in this direction, given the balanced cultures they created and the satisfaction of their players with their athletic experiences.

The academic leaders created less balanced cultures that were more clan oriented. Clan cultures usually enjoy greater employee morale, and in our study, there was a positive correlation between how clannish an academic department was perceived and the students' satisfaction with their major. One could argue that it makes sense for academic cultures to be more clannish because the academic mission is more directly related to student development without having to worry as much about performance measures, such as win-loss percentage. Also, most campus leaders do not receive much formal leadership training. As a faculty member, professors learn how to mentor and develop students in their academic specialty, so as leaders they know how to build clan cultures. They also learn how to monitor and coordinate, so universities tend to be somewhat hierarchical as well. Across the academic departments in our study, the hierarchy dimension was ranked second, after clan, as can be seen in Figure 2. Perhaps it would benefit universities to provide their leaders (chairs and deans) with training in directing, producing, innovating, and brokering in order to build more balanced cultures.

\section{Conclusion and Future Research}

In this study we investigated academic and sports cultures and subcultures using the competing values framework. We contend that the competing values framework is a useful tool for describing and comparing different cultures. Another benefit of the competing values framework is that it can diagnose cultures that may be out of balance and suggests ways that leaders can facilitate cultural changes. Thus, we recommend the competing values framework to campus leaders who want to better understand their team, department, school, and/or university culture. To build a strong culture, organizational leaders need to espouse, enact, and reward behaviors and values that are in line with the desired culture (Hartnell et al., 2011). Having an idea of how the organizational members perceive the current culture is a good first step.

In addition to examining organizational culture, it is useful to explore the relationships between an organization's cultural dimensions and its success criteria. In our study we limited ourselves to student satisfaction, but in future studies we hope to add additional criteria, such as student retention, win-loss records, graduation rates, etc. By exploring student satisfaction, we stumbled across the finding that the female athletes at the university we studied prefer market cultures. Thus, gender moderated the relationship between culture and satisfaction for studentathletes. We wonder whether this finding generalizes to other universities and perhaps to professional sports teams. We wonder how other demographic variables, such as race and ethnicity, might interact with culture and various success criteria. 


\section{References}

Acharya, L., Jin, L., \& Collins, W. (2018). College life is stressful today: Emerging stressors and depressive symptoms in college students. Journal of American College Health, 66, 655664.

American College Health Association (2018). American college health association-national college health assessment II: Reference group executive summary fall 2017. Hanover, MD: American College Health Association. https://www.acha.org/documents/ncha/NCHAII_FALL_2017_REFERENCE_GROUP_EXECUTIVE_SUMMARY.pdf

Aronson, E., \& Mills, J. (1959). The effect of severity of initiation on liking for a group. Journal of Abnormal and Social Psychology, 59, 177-181.

Beam, J. W., Serwatka, T. S., \& Wilson, W. J. (2004). Preferred leadership of NCAA Division I and II intercollegiate student-athletes. Journal of Sport Behavior, 27, 3-17.

Bjorkqvist, K., Osterman, K., \& Lagerspetz, K. M. J. (1994). Sex differences in covert aggression among adults. Aggressive Behavior, 20, 27-33.

Branch, T. (2011). The cartel: Inside the rise and imminent fall of the NCAA. Byliner Inc.

Cameron, K. S., \& Quinn, R. E. (2011). Diagnosing and changing organizational culture: Based on the Competing Values Framework ( $3^{\text {rd }}$ ed.). Jossey-Bass.

Carron, A. V., Colman, M. M., Wheeler, J., \& Stevens, D. (2002). Cohesion and performance in sport: A meta analysis. Journal of Sport and Exercise Psychology, 24, 168-188.

Chelladurai, P., \& Arnott, M. (1985). Decision styles in coaching: Preferences of basketball players. Research Quarterly for Exercise and Sport, 56, 15-24.

Dee, T. S. (2014). Stereotype threat and the student-athlete. Economic Inquiry, 52, 173-182. 
Denison, D. R. (1996). What is the difference between organizational culture and organizational climate? A native's point of view on a decade of paradigm wars. The Academy of Management Review, 21, 619-654.

Denison, D. R., Hooijberg, R., \& Quinn, R. E. (1995). Paradox and performance: Toward a theory of behavioral complexity in managerial leadership. Organization Science, 6, 524540 .

Eagly, A. H., \& Carli, L. L. (2003). The female leadership advantage: An evaluation of the evidence. The Leadership Quarterly 14, 807-834.

Ellis, L., Hershberger, S., Field, E., Wersinger, S., Pellis, S., Geary, D., Palmer, C., Hoyenga, K., Hetsroni, A., \& Karadi, K. (2008). Sex differences: Summarizing more than a century of scientific research. Psychology Press.

Fasting, K., \& Pfister, G. (2000). Female and male coaches in the eyes of female elite soccer players. European Physical Education Review, 6, 91-110.

Fischer, F. T., Schult, J., \& Hell, B. (2013). Sex differences in secondary school success: Why female students perform better. European Journal of Psychology of Education, 28, 529543.

Gayles, J. G. (2009). The student athlete experience. New Directions for Institutional Research, $144,33-41$.

Gerard, H. B., \& Mathewson, G. C. (1966). The effects of severity of initiation on liking for a group: A replication. Journal of Experimental Social Psychology, 2, 278-287.

Graunke, S. S., \& Woosley, S. A. (2005). An exploration of the factors that affect the academic success of college sophomores. College Student Journal, 39, 367-377.

Hampton, G. M., \& Hampton, D. L. (2004). Relationship of professionalism, rewards, market orientation and job satisfaction among medical professionals: The case of certified nursemidwives. Journal of Business Research, 57, 1042-1053.

Hartnell, C. A., Ou, A. Y., \& Kinicki, A. (2011). Organizational culture and organizational effectiveness: A meta-analytic investigation of the competing values framework's theoretical supposition. Journal of Applied Psychology, 96, 677-694. 
Hatch, M. J., \& Cunliffe, A. L. (2006). Organization theory: Modern, symbolic and postmodern perspectives. Oxford University Press.

Heuz’e, J.-P., Sarrazin, P., Masiero, M., Raimbault, N., \& Thomas, J. P. (2006). The relationships of perceived motivational climate to cohesion and collective efficacy in elite female teams. Journal of Applied Sport Psychology, 18, 201-218.

Horn, T. S. (1992). Leadership effectiveness in the sport domain. In T. S. Horn (Ed.) Advances in sport psychology (pp. 181-189). Human Kinetics.

Jermier, J. M., Slocum Jr, J. W., Fry, L. W., \& Gaines, J. (1991). Organizational subcultures in a soft bureaucracy: Resistance behind the myth and facade of an official culture.

Organization Science, 2, 170-194.

Jolly, J. C. (2008). Raising the question \# 9 is the student-athlete population unique? And why should we care? Communication Education, 57, 145-151.

Knapp, L. G., Kelly-Reid, J. E., \& Ginder, S. A. (2012). Enrollment in postsecondary institutions, fall 2010; financial statistics; fiscal year 2010; and graduation rates, selected cohorts, 2002-07. U.S. Department of Education.

Kniffin, K. M., Wansink, B., \& Shimizu, M. (2015). Sports at work: Anticipated and persistent correlates of participation in high school athletics. Journal of Leadership \& Organizational Studies, 22, 217-230.

Kot, F. C. (2014). The impact of centralized advising on first-year academic performance and second-year enrollment behavior. Research in Higher Education, 55, 527-563.

Lee, E. S. (2010). A perception of impropriety: The use of packaging deals in college basketball recruiting. http://digitalcommons.law.villanova.edu/cgi/viewcontent.cgi?article=1050\&context=mslj

Lopiano, D., Gurney, G., Porto, B., Ridpath, D. B., Sack, A., Willingham, M., \& Zimbalist, A. (2016, August). Position statement: Institutional integrity issues related to athlete sexual assault and other forms of serious misconduct. The Drake Group. https://drakegroupblog.files.wordpress.com/2016/09/position-statement-athlete-sexualassault-final1.pdf 
Lovell, B. (2015). "We are a tight community": Social groups and social identity in medical undergraduates. Medical Education, 49, 1016-1027.

Lu, F. J., Hsu, Y., Chan, Y., Cheen, J., \& Kao, K. (2012). Assessing college student-athletes' life stress: Initial measurement development and validation. Measurement in Physical Education and Exercise Science, 16, 254-267.

Lund, D. B. (2003). Organizational culture and job satisfaction. Journal of Business \& Industrial Marketing, 18, 219-236.

Lyall, S. (2014, October 2014). U.N.C. investigation reveals athletes took fake classes. New York Times. https://www.nytimes.com/2014/10/23/sports/university-of-north-carolinainvestigation-reveals-shadow-curriculum-to-help-athletes.html

Maccoby, E. E. (1990). Gender and relationships: A developmental account. American Psychologist, 45, 513-520.

Maccoby, E. E. (1998). The two sexes: Growing up apart, coming together. Harvard University Press.

McBride, R. E., \& Reed, J. (1998). Thinking and college athletes: Are they predisposed to critical thinking? College Student Journal, 32, 443-450.

Meyer, S. K. (2005, Fall). NCAA academic reforms: Maintaining the balance between academics and athletics. Phi Kappa Phi Forum, 15-18.

Milem, J. F., \& Berger, J. B. (1997). A modified model of college student persistence: Exploring the relationship between Astin's theory of involvement and Tinto's theory of student departure. Journal of College Student Development, 38, 387-400.

Miller, K. E., Sabo, D., Melnick, M. J., Farrell, M. P., \& Barnes, G. M. (2006, August). Jocks and athletes: College students' reflections on identity, gender, and high school sports. Paper presented at the American Sociological Association annual meeting, Montreal, Quebec, Canada. 
Moffatt, M. (1991). College life: Undergraduate culture and higher education. Journal of Higher Education, 62, 44-61.

Monrouxe, L. V. (2010). Identity, identification and medical education: Why should we care? Medical Education, 44, 40-49.

Morgan, G. (2006). Images of organization (updated edition). Sage Publications.

Murphy, G. M., Petitpas, A. J., \& Brewer, B. W. (1996). Identity foreclosure, athletic identity, and career maturity in intercollegiate athletes. The Sport Psychologist, 10, 239-246.

Navarro, K. M. (2012). Toward an understanding of career construction in the 21st century: A phenomenological study of the life experiences of graduating student-athletes at a large highly-selective Midwestern university [Doctoral dissertation, University of Wisconsin].

Officer, S. A., \& Rosenfeld, L. B. (1985). Self-disclosure to male and female coaches by female high school athletes. Journal of Sport Psychology, 7, 360370.

Pond, S. B., \& Geyer, P. D. (1991). Differences in the relation between job satisfaction and perceived work alternatives among older and younger blue-collar workers. Journal of Vocational Behavior, 39, 251-262.

Potuto, J. R., \& O’Hanlon, J. (2007). National study of student-athletes regarding their experiences as college students. College Student Journal, 41, 947-967.

Quinn, R. E., \& Rohrbaugh, J. (1983). A spatial model of effectiveness criteria: Towards a competing values approach to organizational analysis. Management Science (Pre-1986), 29, 363.

Quinn, R. E., \& Shepard, L. (1974). The 1972-1973 Quality of employment survey: Source book descriptive statistics with comparison data from the 1969-1970 survey of working conditions. University of Michigan, Institute of Social Research.

Quinn, R. E., \& Spreitzer, G. M. (1991). The psychometrics of the competing values culture instrument and an analysis of the impact of organizational culture on quality of life. In R. W. Woodman \& W. A. Pasmore (Eds.), Research in organization change and development, vol. 5: 115-142. JAI Press. 
Rosenfeld, L. B., Civikly, J. M., \& Herron, J. R. (1979). Anatomical and psychological sex differences. In G.J. Chelune (Ed.), Self-disclosure (pp. 80-109), Jossey-Bass.

Rosenfeld, P., Giacalone, R. A., \& Tedeschi, R. (1984). Cognitive dissonance and impression management: Explanations for effort justification. Personality and Social Psychology Bulletin, 10, 394-401.

Schein, E. H. (2010). Organizational culture and leadership (4 ${ }^{\text {th }}$ ed.). Jossey-Bass.

Schmidt, W. E. (1986, January 14) Education: Bending the rules for student athletes. New York Times. https://www.nytimes.com/1986/01/14/science/education-bending-the-rules-forstudent-athletes.html

Schneider, B., Ehrhart, M. G., \& Macey, W. H. (2013). Organizational climate and culture. Annual Review of Psychology, 64, 361-388.

Simons, H. D., Bosworth, C., Fujita, S., \& Jensen, M. (2007). The athlete stigma in higher education. College Student Journal, 41, 251-273.

Southall, R. M., \& Weiler, J. D. (2014). NCAA Division-I athletic departments: 21st century athletic company towns. Journal of Issues in Intercollegiate Athletics, 7, 161-186.

Sparent, M. E. (1989). The student-athlete in the classroom: The impact of developmental issues on college athletes' academic motivation and performance. Research \& Teaching in Developmental Education, 5, 7-16.

Steffens, N. K., Haslam, S. A., Jetten, J., \& Mols, F. (2018). Our followers are lions, theirs are sheep: How social identity shapes theories about followership and social influence. Political Psychology, 39, 23-42.

Steinfeldt J. A., Carter, H., Benton, E., \& Steinfeldt, M. C. (2011). Muscularity beliefs of female college student-athletes. Sex Roles, 64, 543-554.

Stone, J., \& Cooper, J. (2001). A self-standards model of cognitive dissonance. Journal of Experimental Social Psychology, 37, 228-243. 
Terry, P. C. (1984). The coaching preferences of elite athletes competing at Universiade '83. Canadian Journal of Applied Sport Sciences, 9, 201-208.

Thamel, P. (2006, November 4). Athletes get new college pitch: Check out our tutoring center. New York Times. https://www.nytimes.com/2006/11/04/sports/ncaafootball/04ncaa.html

Tinto, V. (1993). Leaving college: Rethinking the causes and cures of student attrition (2nd ed.). The University of Chicago Press.

Tomlinson, A., \& Yorganci, Y. (1997). Male coach/female athlete relations: Gender and power relations in competitive sport. Journal of Sport \& Social Issues, 21, 134-155.

Weaver, R., Peters, K., Koch, J., \& Wilson, I. (2011). "Part of the team": Professional identity and social exclusivity in medical students. Medical Education, 45, 1220-1229.

Wrisberg, C. A. (1996). Quality of life for male and female athletes. Quest, 48, 392-408.

Yopyk, D. J., \& Prentice, D. A. (2005). Am I an athlete or a student? Identity salience and stereotype threat in student-athletes. Basic and Applied Social Psychology, 27, 329-336.

Zammuto, R. F., \& Krakower, J. Y. (1991). Quantitative and qualitative studies of organizational culture. In W. A. Pasmore \& R. W. Woodman (Eds.) Research in organization change and development, vol. 5: 83-114. JAI Press.

Zavyalova E., \& Kucherov, D. (2010). Relationship between organizational culture and job satisfaction in Russian business enterprises. Human Resource Development International, $13,225-235$. 